thod seems to offer considerable promise for the study of optical and absorption spectra of, particularly, non-transparent solids and liquids. High energy electron diffraction theory has been refined to take care of inelastic effects so that this method is now a more valuable tool to the experimenter. Low energy, high resolution photoemission techniques have been used to demonstrate, for example, the change in the electronic structure caused by melting. Then we have polarized electron emission, Auger spectroscopy and the range of measu- rements that can be made with synchrotron radiation varying from the use of X-ray absorption techniques to high angular resolution of UV photoemission which permits the direct determination of the electronic band structure. In this general area of photoemission processes, important advances have also been made in the theory which allows a better understanding of the significance of experimental determinations.

\section{Françoise Houzay and Lubomir Skala}

\section{Exhibition}

Centrally placed in the exhibition mounted at York was a series of panels explaining the basic principles and the characteristics of synchrotron radiation, tracing its development as an experimental technique from the time the effect was first observed.

Because the radiation energy can be so precisely controlled and fo- cused, medical radiography and, in particular, tomography, are bound to benefit. Using small-angle scattered radiation at, say, $140 \AA$, provides a powerful means for the study of biological substances and has already furnished us with a clearer understanding of the functioning of muscle tissue through its fine time resolution. In topographical applications, magnetic domains and crystal structures can be studied with a precision and rapidity never reached before.

The specialized lectures on X-ray spectroscopy and crystallography, fluorescent analysis and on structural research on biological substances made the point very clearly that, with the advent of synchrotron radiation facilities, experimental physics has taken another leap forward.

In other sections of the general exhibition, five examples of modern instrumentation were presented, a reminder that industry is keeping pace with the high demands of the presentday experimental physicist. Information was given also on techniques developed for the remote measurement of physical parameters. Publishers showed that they cater for the increasing demand and supply of printed information which the publication explosion brings with it, and INSPEC of the Institution of Electrical Engineers provided a computer terminal with access to abstracts and reference data, a service appreciated by many visitors.

\title{
Education and Popularization
}

The laws of evolution require that attention be paid to the continuation of the species. Of course, this does not mean that physicists should think solely about the reproduction of the species of physicists, but the problem is none the less important. In the past, the problem of how to teach physics has in the main been the province of fanatics, but more and more it has become a matter of concern for physicists in general. It is significant that at York, the lecture by Prof. R. Fuller on this subject was included in the plenary session programme, and it was a matter of much regret that Prof. Jean Piaget did not feel well enough to participate. The Workshop on Physics Teaching was expected to attract about 30 participants but more than double asked to take part.

The main problem is to find a language in which we can talk about the teaching and learning of physics. Prof. Fuller, a dedicated and articulate disciple of Jean Paget, sought to illustrate his principles by involving his audience - a process that fascinated many but did not convince all. Piaget, without penetrating the methodology of physics, tries to explain the process of cognition and reasoning (understanding) of the physical world. As described in EN, 9
(1978) 4, p. 11, he identifies the following phases of cognitive development: sensory-motor, pre-operational, concrete-operational, formal-operational. They are described by the ability to solve certain physical problems, and are based on tests which appreciate the skill in a critical approach to physical observations. It is useful to recapitulate briefly these stages. The first, sensory-motor pre-verbal stage covers the first 18 months of life. During this stage, constructions such as the permanent existence of objects, temporal succession and elementary sensory-motor causality, are developed. The beginnings of language, of symbolic function of representation is attributed to the second stage: preoperational. In the third stage, actions appear which operate on objects, but not yet on verbally expressed hypotheses. These are operations of classification, ordering, the idea of number, etc., and even the fundamental operations of elementary logic of classes and relations, elementary mathematics and physics. The fourth stage: formal-operational, can be called hypothetic-deductive. In this stage the child can reason on hypotheses, not only on objects. This is the level on which completely abstract reasoning is possible.

The development of formal reason- ing should be an explicit aim of education, and the teaching of physics must conform with this scheme. It must also acknowledge the "boundary conditions" i.e. it must be adapted to the phase of cognitive development of the students and must provoke their further development in a proper way.

Contrary to the traditional technique of "pouring knowledge into heads", the only natural ways of teaching are the so-called active methods. They are characterized by the following factors:

autonomy - no strict control over the activity of students

\section{Job Opportunity for an \\ Experimental Physicist}

There is an opening for a post-doc or more senior scientist at the Labor. Für Hochenergiephysik der Eidgenössischen Technischen Hochschule (ETH) in Zürich. Experimental physictsts who are interested in doing and planning medium energy particle physics experiments at the Schweizerische Institut für Nuklearforschung (SIN) should write to :

Dr. P.G. Seiler

Laboratorium für Hochenergiephysik

Eidgenössische Technische Hochschule c/o SIN

$\mathrm{CH}-5234$ Villigen / Switzerland 
freedom of action - not following step by step predetermined directions

time for reflection

resolution of contradictions.

This scheme is basic for so called self-regulation methods or Piaget's "equilibration": "In the act of knowing, the subject is active, and consequently, faced with an external disturban$\mathrm{ce}$, he will react in order to compensate, and consequently he will tend toward equilibrium". (J. Piaget, Journal of Research and Sci. Teaching, 2 (1964) 176-186.

These ideas of Piaget, his followers maintain, should be taken into consideration in new curricula of physics, as for instance in the "Nebraska Program of Teaching Physics" (R. Karplus). The basis for this program is a "learning circle" consisting of the following steps:

exploration - open flexible experiments with objects in small groups

concept introduction - define concepts by lead person based on the first phase

concept's application - going to new system.

Of great assistance in understanding the above ideas was the "Workshop on Physics Teaching and the Development of Reasoning" organized during the EPS-4 Conference on the lines of a workshop already held by the American Association of Physics Teachers. The following is a brief resume of the Workshop programme.

Module 1 "How people think". Many students do not use reasoning patterns that seem to be obvious. By comparing their own solutions of tests with student's solutions, participants were able to distinguish between various patterns of thought used to solve simple problems.

In the next Modules 2, 3, 4, "Concrete and Formal Thought" the idea of concrete level and formal level thought was introduced as defined in

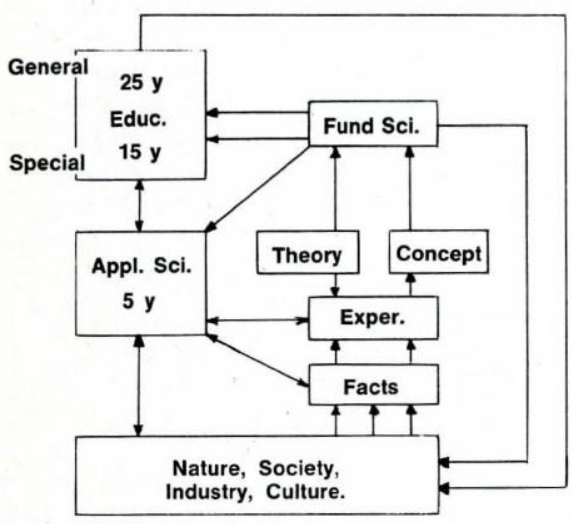

\section{New I.O.M.s Accepted}

CATEGORY 4 A

D.-S. Chemla, Bagneux, F

P. Lascaux, Villeneuve

St. Georges, F

D. Mead, Stuttgart, D

\section{CATEGORY $4 \mathrm{C}$}

Belgian Physical Society : The Netherlands' Physical J.-P. Gaspard, Sart-Tilman Society :

French Physical Society : J. Heijboer, Delft

C. Faure, Ozoir la Ferrière - B.P.Th. Veltman, Voerschoten Lesigny

German Physical Society : Spanish Royal Society of

E. Lebsanft, Jülich

W. Schmidt, Aalen

The Institute of Physics :

I. Belal, Damascus,

Syrian Arab Repubilc

D. Kalymnios, Piraeus, GR

H. Lightblau,

Sunbury on Thames
F.J. de Hoog, Nuenen

talian Physical Society :

M. Bertoni, Modena

F. Manghi, Modena

F. Nizzoli, Modena

I. Ortalli, Parma

M. Weenink, Stiphout

Physics and Chemistry :

R. Alcala, Zaragoza

Swedish Physical Society :

D. Noréus, Spanga

M.A. Raadu, Stockholm

R. Riklund, Linköping

B. Sandell, Ureta Kloster

O. Skeppstedt, Askim
Physical Section, Union of Yugoslav Societies of Mathematicians, Physicists and Astronomers :

R. Antanasijevic, Belgrade

I. Cadez, Belgrade

V. Cadez, Belgrade

M. Cerineo, Belgrade

S. Cvejanovic, Belgrade

L. Dobrosavljevic, Belgrade

B. Dragovic, Belgrade

P. Grujic, Belgrade

R. Janev, Belgrade

J. Jovanovic-Kurepa

N. Konjevic, Belgrade

V. Pejcev, Belgrade

M. Popovic, Belgrade

S. Popovic, Belgrade

M. Popovic-Bozic, Belgrade

Z. Todorovic, Belgrade

M. Tripkovic, Belgrade

V. Urosevic, Belgrade

S. Vukovic, Belgrade

L. Vuskovic, Belgrade
Piaget's theory. There were presented relations (films and video-tape) on students' responses to typical Piaget tasks.

Recent research results obtained by similar methods were presented in Module 5. They included the classification of 14-16 years old college students' responses which varied from $12 \%$ for the concrete-operational level and $48 \%$ formal-level responses (Fuller) to $50 \%$ concrete and $25 \%$ formal level (J. McKinnon, J. Renner, Am. J. Phys. 39 (1971) 1047.

The last modules were devoted to methods of analysis of test questions, textbooks and to strategies of teaching.

Education should not be orientated only towards the production of more physicists. Consideration has to be given to the development of really high quality research - something of a rarity. Current studies aim to try and analyse the ratio of high-value to low-value research so that quality can also be taken into account in education methods.

\section{Popularization}

Moreover, education does not stop there. Physicists are becoming more conscious of their responsibilities toward society, the interaction being illustrated in the accompagnying figure. A part of this interaction concerns the education of the public, the "popularization" of physics. Teaching and popularization fuse into each other as the public is not a homogeneous bloc but constitutes a wide variety of different people of differing experiences and interests who consequently have differing needs.

Two recent experiments in communication illustrate this point. In Poitiers (France) over a period of some two months the general public was able to enter into direct contact with scientists and discuss what was in their mind. They could also participate in experiments. Attendance was unexpectedly high and covered a broad cross-section of the population.

At IKO in Amsterdam a deliberate effort was made to reach the professional (but non-Scientific) staff of the institute, not only by giving popular lectures but by listening to proposals and then analysing the attitudes of the scientists, laymen and students, that emerged. The meeting in York demonstrated that education and popularization are no longer "fringe" activities.

\section{Pawel Kruszynski and Jan Vlachy}

Editor : E.N. Shaw

Meetings compilation : W.S. Newman

Editorial Board :

G.J. Béné, G.R. Macleod, A. Maeder J. Muller, D. Pohl, J.A. Schwarzmúller

All correspondance to

Editor, EUROPHYSICS NEWS,

European P. Box 69

P.O. Box 69,
H-1213 Petit-Lancy 2

Switzerland

Te. Geneva 931130 Tx. 23455 alarm ch

Published by the European Physical Society

Printed by : Ed. Cherix et Filanosa SA CH-1260 Nyon, Switzerland 